\title{
AC 2009-2327: EXPERIENCES WITH ASSESSMENT TESTS FOR SYSTEMS COURSES
}

\section{Tokunbo Ogunfunmi, Santa Clara University}

TOKUNBO OGUNFUNMI, Ph.D., P.E. is an Associate Professor of Electrical Engineering at Santa Clara University, Santa Clara, California. He earned his BSEE (First Class Honors) from Obafemi Awolowo University (formerly University of Ife), Nigeria, his MSEE and PhDEE from Stanford University, Stanford, California. His teaching and research interests span the areas of Digital Signal Processing (theory, applications and implementations), Adaptive Systems, VLSI/ASIC Design and Multimedia Signal Processing. He is a Senior Member of the IEEE, Member of Sigma Xi, AAAS and ASEE. 


\title{
Experiences with Assessment Tests for Systems Courses
}

\author{
Abstract \\ Linear (Signals and) Systems and Digital Signal Processing courses are core components of \\ undergraduate curricula in electrical engineering programs worldwide. \\ The Signals and Systems Concept Inventory (SSCI) is a set of multiple-choice questions that \\ measures students' understanding of fundamental concepts in continuous-time and discrete-time \\ systems. There are two versions of the SSCI Tests. One deals with Continuous-Time (CT) \\ systems and the other deals with Discrete-Time (DT) systems. \\ Since Fall 2005, the CT SSCI Tests has been administered in every offering of our Linear \\ systems course. The DT SSCI Tests has also been administered in the subsequent course on \\ Digital Signal Processing. We have much data from both tests. The tests fulfill the ABET \\ requirement for assessment. It also helps track the effectiveness of teaching styles by testing \\ whether the students are learning the basic concepts in the course. \\ In this paper, we present and analyze recent results of our SSCI CT Tests in the Linear Systems \\ course. We analyze the results to assess the students' performance from year to year and \\ determine evidence of learning outcomes. We offer useful suggestions for future offerings of the \\ courses based on our findings. Some conclusions are made on whether we meet our assessment \\ goals and on the efficacy of the SSCI CT Tests.
}




\section{Introduction}

A course in linear (signals and) systems is a core component of undergraduate curricula in electrical engineering programs worldwide. Typically the course is offered at the junior level [1]. At Santa Clara University, the course is titled "Linear Systems" and taken by all juniors in the Fall term/semester.

Over the last two years when the author has taught the course, an assessment of the student learning outcomes have been done using primarily a standard test known as the SSCI.

The Signals and Systems Concept Inventory (SSCI) [2-3] is a set of multiple-choice questions that measures students' understanding of fundamental concepts such as signal transformations, linearity, time-invariance, transforms, convolution, etc. There are two versions of the SSCI for Linear Systems. One deals with Continuous-Time (CT) systems and the other deals with Discrete-Time (DT) systems.

The paper is divided into six sections. In Section 2, we describe the Linear Systems course contents. In Section 3, we briefly describe the SSCI CT Test which has been administered in our Linear systems classes since 2005. The SSCI CT Test is given to assess the students' performance and determine evidence of learning outcomes. In Sections 4 and 5, the results from the two recent offerings of the tests are presented and analyzed. In the Concluding section, some suggestions for future offerings of the course are presented. The efficacy of the tests to help us achieve our stated goals are determined.

Prior SSCI CT Tests results have been presented and analyzed in [4].

The goals of our on-going study are :

(1) To determine how much conceptual understanding the students have developed by the end of the class (compared to the beginning of the class).

(2) To correlate the performance on the end-of-term exam with the performance on the SSCI Post-Test which is designed to test the conceptual understanding, but not necessarily the steps of problem solving and system design.

(3) To determine the concepts which the students have had difficulty understanding so that there may be more emphasis on those concepts the next time the course is offered.

(4) To recommend alternate pedagogical methods for presenting the material in the Linear Systems course based on the results of our study. 


\section{The Linear Systems Course}

The Linear Systems course is a junior-level course and is a pre-requisite to most control, communications, signal processing and other "system"-type technical elective courses that are taken at the senior level. We have modified this course since its inception. We also emphasize use of MATLAB in this course as well as in most of our ELEN courses.

\section{$\underline{\text { Course Contents }}$}

Our Linear Systems course requires the completion of the Electric Circuits I and II sequence. This course deals with the fundamentals of Linear Systems.

We cover topics such as description and analysis of continuous-time and discrete-time signals and systems, differential equations and difference equations, convolution, Z-transforms, transfer function. The Fourier Series, Fourier Transforms, Fourier Integral, etc. (see course outline for more details).

In short, there are five main parts to this course:

1. Continuous-Time (CT) Signals,

2. Continuous-Time (CT) Systems

3. Fourier Series

4. Transforms (Laplace, Fourier, Z)

5. Discrete-Time (DT) Signals

6. Discrete-Time (DT) Systems

\section{$\underline{\text { Lab Contents }}$}

The laboratory part of the course consists of five laboratory assignments. Some of the labs require the use of MATLAB. The titles of the labs are :

Lab 1: Review of Laplace Transforms

Lab 2: Convolution and Impulse Response

Lab 3: Fourier Series

Lab 4: Testing Fourier Transforms

Lab 5: Digital Simulator.

Many universities, including ours, continually strive to improve their programs by assessing its impact and learning outcomes and modifying, changing or deleting, adding courses based on academic and industrial technology trends. This is actually required by the Accreditation Board for Engineering Technology (ABET) as part of accreditation requirements. Assessment of Student Learning Outcomes is also part of ABET Accreditation requirements.

The SSCI Tests help us fulfill the ABET Assessment requirements.

We now briefly describe the SSCI CT Test. 


\section{The Signals and Systems Concept Inventory (SSCI) Tests}

Here follows some description of the SSCI CT Test. Details can be found in [2].

\section{Questions 1-4, 14}

These questions are about Math and most of the students answered them correctly as shown in Table 1. These are not difficult questions. The concepts tested are time/frequency signal plots, time reversal, time shifts and signal transformations. Question 14 tests the recognition of the form of the solution to a LCCDE with sinusoidal forcing functions in a differential equation.

\section{Questions 5,23, and 24}

These questions are about Linear Time-invariant (LTI) systems. Recognizing linear and timeinvariance properties are important. Also, the analytical tools required such as convolution, properties of convolution are tested. Determination of the property of a system given its input and output signals tests the students' ability to synthesize these properties by reverse thinking processes.

\section{Questions 6, 7, 9-11, 13, 15-22, 25}

These questions test the transform properties with applications to pole-zero plots, Fourier series, etc. Many of the questions involve relating two or more concepts such as time-domain signals, with filtering, with pole-zeros plots. Question 22 tests Bode Plots. Bode Plots were not taught in this class but is part of the pre-requisite class; Electric Circuits II. So, it is obvious that the students may not expect this problem and may have forgotten the topic of Bode plots.

\section{Questions 8, 15, 23}

These questions test the concept of convolution and its properties when applied to a Linear, timeinvariant (LTI) system.

The two parts of the SSCI Test (CT and DT) are described more fully in [2].

This reference details the multiple-choice tests and the way the tests were developed and how to apply them. Our focus here is on the Continuous-time (CT) test.

On the first and last day of class, we tested all the students in the course using the SSCI CT Test. The test is not mandatory but optional. However, bonus points are awarded just for taking the test. Some students missed the test or decided not to take it. 


\section{Results of the Fall 2007 SSCI CT Pre- and Post-Test as an Assessment Tool}

The results of our SSCI CT Pre- and Post- tests are discussed and analyzed as follows in Tables 1 and 2:

Table 1 : Pre- and Post-Test Results for Fall 2007 class.

PRE-TEST

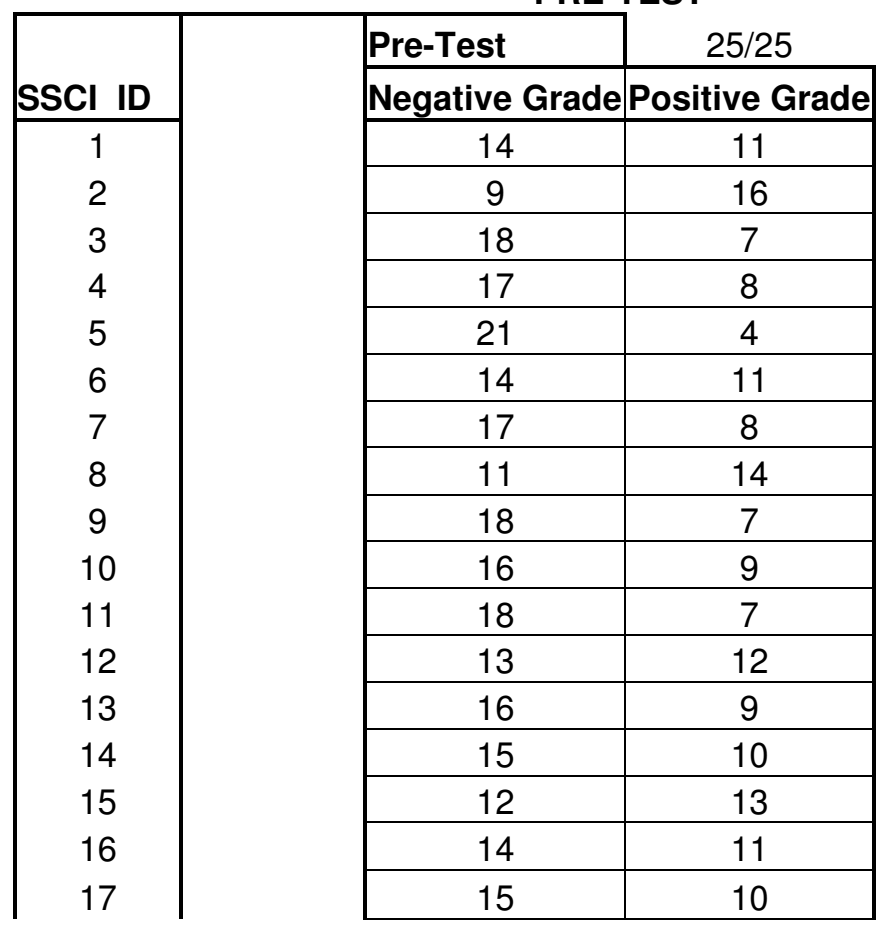

\begin{tabular}{|c|c|}
\multicolumn{2}{|c|}{ POST-TEST } \\
\hline Post-Test & $25 / 25$ \\
\hline Negative Grade & Positive Grade \\
\hline 5 & 20 \\
\hline 12 & 13 \\
\hline 13 & 12 \\
\hline 9 & 16 \\
\hline 14 & 11 \\
\hline 8 & 17 \\
\hline 6 & 19 \\
\hline 10 & 15 \\
\hline 14 & 11 \\
\hline 14 & 11 \\
\hline 13 & 12 \\
\hline 14 & 11 \\
\hline 10 & 15 \\
\hline 10 & 15 \\
\hline & \\
\hline 12 & 13 \\
\hline 15 & 10 \\
\hline
\end{tabular}

Student number 15 dropped the class or did not take the post-test.

The overall pre-test mean score for all the 17 students is Sum / $17=9.823$.

The maximum score is $16 / 25$. The minimum score is $4 / 25$.

The overall post-test mean score for all the 16 students is Sum / $16=13.8125$.

The maximum score is $20 / 25$. The minimum score is $10 / 25$.

It is expected that Post-Test grades will be higher than Pre-Test grades as evidence of student learning. This is true here except in three cases. Two cases have lower Post-Test score than PreTest score and one student scored the same on both Pre- and Post-Tests. To better measure the correlation between Pre-test and Post-Test results, we compute $<\mathrm{g}>$ which is introduced as the normalized gain as defined and used in [2]. 
The $<\mathrm{g}>$ parameter (defined as $<\mathrm{g}>=$ (post-pre)/(100-pre)) helps us quantify student learning during the course. A positive $<\mathrm{g}>$ indicates performance improvement. The value of $100<\mathrm{g}>\%$ shows student incremental learning or gain in knowledge during the course as a percentage.

See Table 2 for the $<\mathrm{g}>$ scores for Fall 2007 class.

\begin{tabular}{|c|c|c|c|c|c|c|c|c|c|c|c|c|c|}
\hline Student & 1 & 2 & 3 & 4 & 5 & 6 & 7 & 8 & 9 & 10 & 11 & 12 & 13 \\
\hline$<\mathrm{g}>$ & $\begin{array}{c}0.10 \\
1124\end{array}$ & $\begin{array}{c}- \\
0.03 \\
571\end{array}$ & $\begin{array}{l}0.053 \\
763\end{array}$ & $\begin{array}{l}0.086 \\
957\end{array}$ & $\begin{array}{l}0.072 \\
917\end{array}$ & $\begin{array}{l}0.067 \\
416\end{array}$ & $\begin{array}{l}0.119 \\
565\end{array}$ & $\begin{array}{l}0.011 \\
628\end{array}$ & $\begin{array}{l}0.043 \\
011\end{array}$ & $\begin{array}{l}0.021 \\
978\end{array}$ & $\begin{array}{l}0.053 \\
763\end{array}$ & $\begin{array}{l}- \\
0.011 \\
36\end{array}$ & $\begin{array}{l}0.065 \\
934\end{array}$ \\
\hline Student & 14 & 15 & 16 & 17 & & & & & & & & & \\
\hline$\langle\mathrm{g}\rangle$ & $\begin{array}{l}0.055 \\
556\end{array}$ & N/A & $\begin{array}{l}0.022 \\
472 \\
\end{array}$ & 0.0 & & & & & & & & & \\
\hline
\end{tabular}

Table 2 : The $<$ g $>$ scores for Fall 2007 class.

Another way to display the result is to plot the histograms of Pre- and Post-Test results. Here's an example of the histogram for the pre-test and post-test data for Fall 2006:

\begin{tabular}{rrr}
\hline Bin & \multicolumn{1}{r}{ Frequency } \\
\hline & 0 & 0 \\
5 & 0 \\
10 & 13 \\
15 & 17 \\
20 & 3 \\
& 0 \\
& 25 & 0 \\
More & & 0 \\
\hline
\end{tabular}

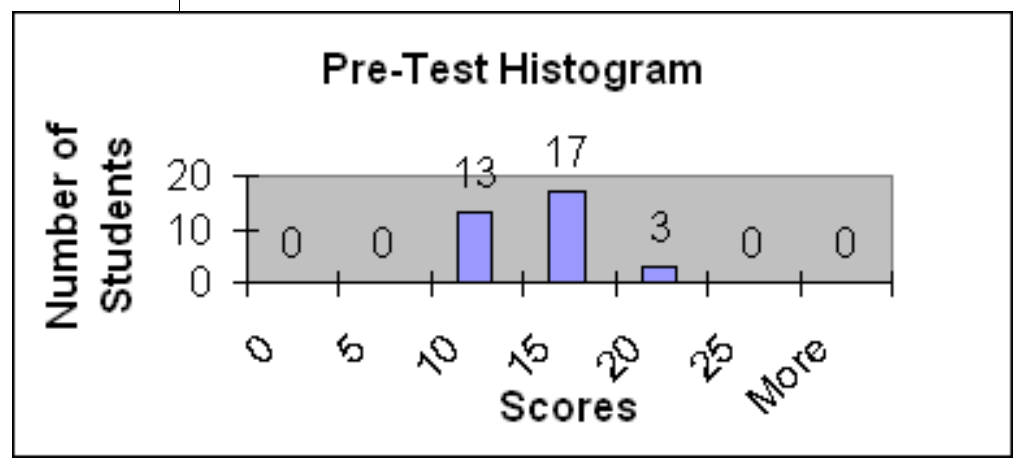

\begin{tabular}{rrr}
\hline Bin & \multicolumn{1}{c}{ Frequency } \\
\hline & 0 & 2 \\
& 5 & 0 \\
10 & 3 \\
15 & 17 \\
& 20 & 9 \\
& 25 & 3 \\
More & & 0 \\
\hline
\end{tabular}

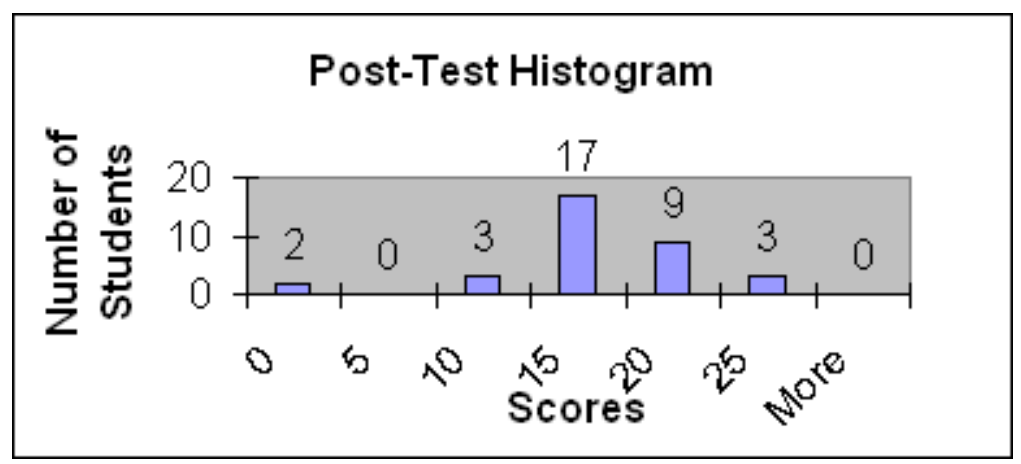

Table 3 : Histograms for Pre- and Post-Test Results for Fall 2006 class.

Table 2 shows that Negative $<\mathrm{g}>$ means Post-Test result was worse than Pre-Test result. Zero $<\mathrm{g}>$ means no improvement and Positive $<\mathrm{g}>$ means Post-Test result was better than Pre-Test result which signals improved learning of signals and systems concept as a result of the course. 
It is clear from any of these results that the performance of the students improved at Post-test compared to Pre-Test.

We can also look to see if there is any direct correlation between the Overall Class Rank and the Rank in the SSCI CT Post-Test. SSCI measures conceptual understanding while the class exams measures mastery of the class subject and the overall ability to solve problems.

Table 4 below shows the comparisons between Rank in Class and Rank in Post-Test.

Table 4 : Fall 2007 Comparing Class Exam and SSCI CT Test Rankings
\begin{tabular}{|c|c|c|c|}
\hline Class ID & $\begin{array}{c}\text { Rank in Class } \\
\mathbf{1} \text { to 20 }\end{array}$ & $\begin{array}{c}\text { Rank in SSCI CT } \\
\text { Post-Test }\end{array}$ & $\begin{array}{c}\text { SSCI CT PT Grade } \\
\mathbf{2 5} / 25\end{array}$ \\
\hline $\mathbf{1}$ & $\mathbf{3}$ & $\mathbf{1}$ & 20 \\
\hline $\mathbf{2}$ & $\mathbf{1 6}$ & $\mathbf{8}$ & 13 \\
\hline $\mathbf{3}$ & $\mathbf{9}$ & $\mathbf{1 0}$ & 12 \\
\hline $\mathbf{4}$ & $\mathbf{4}$ & $\mathbf{4}$ & 16 \\
\hline $\mathbf{5}$ & $\mathbf{1 4}$ & $\mathbf{1 2}$ & 11 \\
\hline $\mathbf{6}$ & $\mathbf{7}$ & $\mathbf{3}$ & 17 \\
\hline $\mathbf{7}$ & $\mathbf{1 7}$ & $\mathbf{2}$ & 19 \\
\hline $\mathbf{8}$ & $\mathbf{1 5}$ & $\mathbf{5}$ & 15 \\
\hline $\mathbf{9}$ & $\mathbf{5}$ & $\mathbf{1 2}$ & 11 \\
\hline $\mathbf{1 0}$ & $\mathbf{8}$ & $\mathbf{1 2}$ & 11 \\
\hline $\mathbf{1 1}$ & $\mathbf{1}$ & $\mathbf{1 0}$ & 12 \\
\hline $\mathbf{1 2}$ & $\mathbf{1 2}$ & $\mathbf{1 2}$ & 11 \\
\hline $\mathbf{1 3}$ & $\mathbf{2}$ & $\mathbf{5}$ & 15 \\
\hline $\mathbf{1 4}$ & $\mathbf{1 0}$ & $\mathbf{5}$ & 15 \\
\hline $\mathbf{1 5}$ & $\mathbf{1 1}$ & $\mathbf{1 7}$ & 0 \\
\hline $\mathbf{1 6}$ & $\mathbf{1 3}$ & $\mathbf{8}$ & 13 \\
\hline $\mathbf{1 7}$ & $\mathbf{6}$ & 16 & 10 \\
\hline
\end{tabular}

Comparing the class rankings in the standard exams and in the SSCI CT Test (see Table 4), it is easy to see that there's a correlation between students who do well in the standard exams and those who do well in the conceptual tests. The students whose score are not correlated suggest that they may be good at solving design and mechanistic problems, requiring step-by-step procedure but not good at conceptual understanding. The reverse is also true. This suggests that we need to improve our teaching style to accommodate these students pre-disposition to their individual learning styles.

We can also look into details of student performance from Pre- to Post-test in each of the questions of the SSCI Test. That way we can track each student performance on each question. 


\section{Results of the Fall 2008 SSCI CT Pre- and Post-Test as an Assessment Tool}

On the first and last days of class, we tested all the 26 students in the class using the SSCI CT Test. The results are the Pre-Test and Post-Test results shown in Tables 5, 6 and 7 below. The results are discussed and analyzed subsequently.

Table 5 : Pre- and Post-Test Results for Fall 2008 class.

\begin{tabular}{|c|c|c|c|c|}
\hline \multirow[b]{3}{*}{ SSCI ID } & \multicolumn{2}{|c|}{ PRE-TEST } & \multicolumn{2}{|c|}{ POST-TEST } \\
\hline & Pre-Test & $25 / 25$ & Post-Test & $25 / 25$ \\
\hline & \multicolumn{2}{|c|}{ Negative Grade Positive Grade } & \multicolumn{2}{|c|}{ Negative Grade Positive Grade } \\
\hline 1 & 12 & 13 & 12 & 13 \\
\hline 2 & 9 & 16 & 7 & 18 \\
\hline \multirow{2}{*}{$\begin{array}{l}3 \\
4\end{array}$} & 13 & 12 & 14 & 11 \\
\hline & 12 & 13 & 11 & 14 \\
\hline 5 & 14 & 11 & 12 & 13 \\
\hline \multirow{2}{*}{$\begin{array}{l}6 \\
7\end{array}$} & 13 & 12 & 5 & 20 \\
\hline & 16 & 9 & 14 & 11 \\
\hline 8 & 18 & 7 & 13 & 12 \\
\hline 9 & & & 11 & 14 \\
\hline \multirow{2}{*}{$\begin{array}{l}10 \\
11\end{array}$} & 15 & 10 & 12 & 13 \\
\hline & 11 & 14 & 9 & 16 \\
\hline 12 & 13 & 12 & 10 & 15 \\
\hline \multirow{2}{*}{$\begin{array}{l}13 \\
14\end{array}$} & 12 & 13 & 9 & 16 \\
\hline & 13 & 12 & 9 & 16 \\
\hline 15 & 15 & 10 & 8 & 17 \\
\hline \multirow{2}{*}{$\begin{array}{l}16 \\
17\end{array}$} & 12 & 13 & 11 & 14 \\
\hline & 15 & 10 & 13 & 12 \\
\hline \multicolumn{5}{|l|}{18} \\
\hline 19 & 14 & 11 & 12 & 13 \\
\hline \multicolumn{5}{|l|}{20} \\
\hline \multirow{2}{*}{$\begin{array}{l}21 \\
22\end{array}$} & 15 & 10 & 9 & 16 \\
\hline & 16 & 9 & 10 & 15 \\
\hline 23 & 15 & 10 & 14 & 11 \\
\hline \multirow{2}{*}{$\begin{array}{l}24 \\
25\end{array}$} & 15 & 10 & 7 & 18 \\
\hline & 14 & 11 & 12 & 13 \\
\hline 26 & 12 & 13 & 9 & 16 \\
\hline
\end{tabular}

We also display in Tables 6 and 7 the details of the scores in each Question by each Student. An entry of " 1 " indicates the answer was right and a " 0 " indicates the answer was wrong. 
Table 6 : Details of the Results of the Fall 2008 SSCI CT Pre-Test

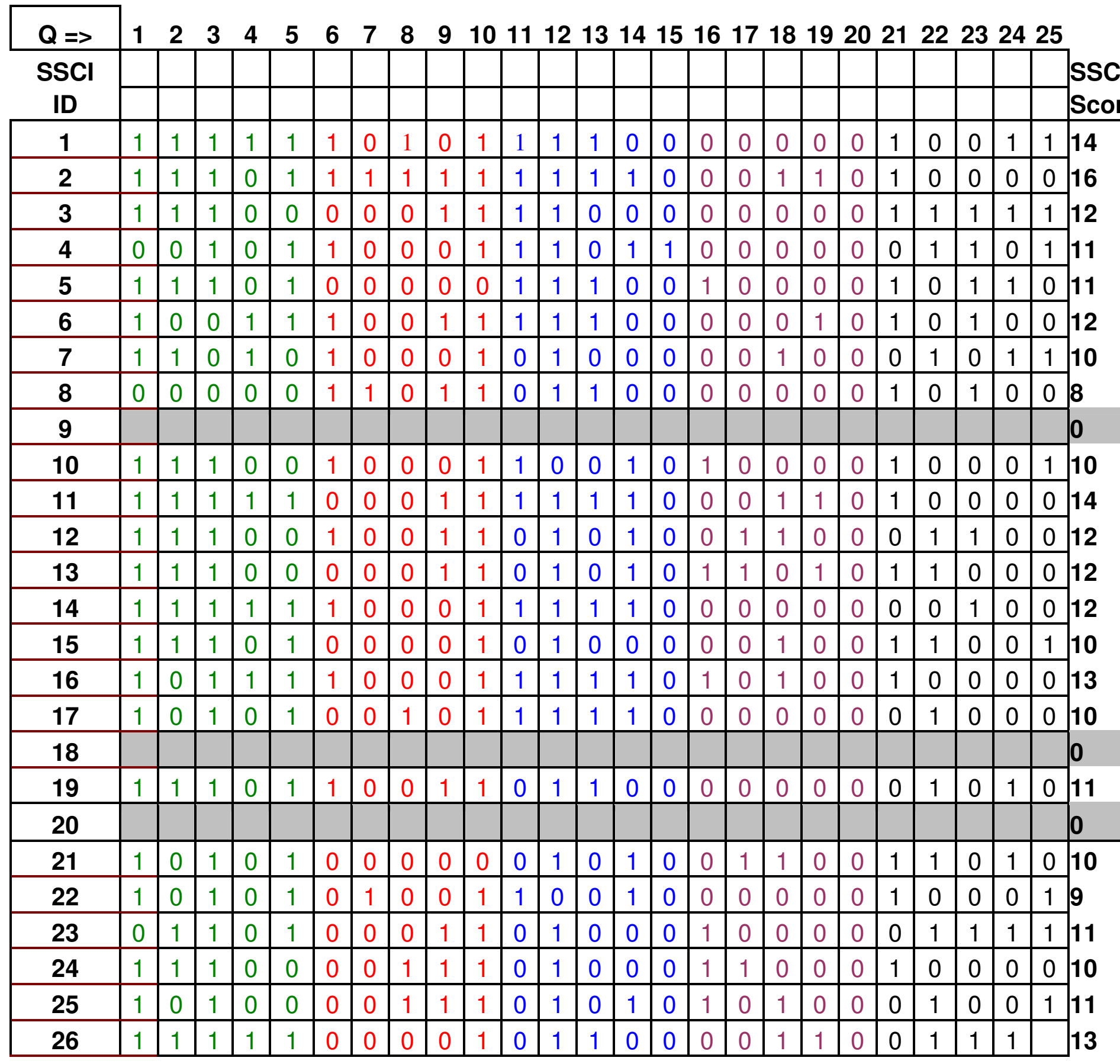

\begin{tabular}{|l|l|l|l|l|l|l|l|l|l|l|l|l|l|l|l|l|l|l|l|l|l|l|l|l|l|}
\hline \#Right & 20 & 15 & 20 & 7 & 15 & 11 & 3 & 5 & 11 & 21 & 12 & 21 & 11 & 12 & 1 & 7 & 4 & 9 & 5 & 0 & 14 & 12 & 9 & 8 & 9 \\
\hline
\end{tabular}

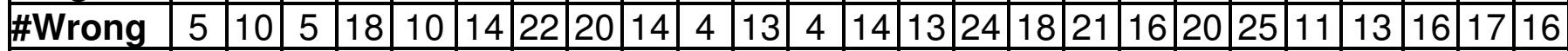

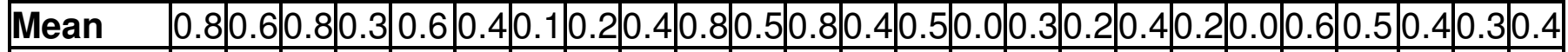

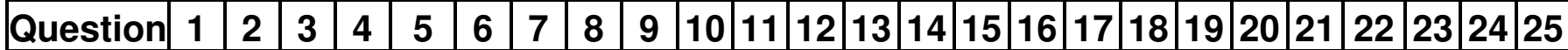


Table 7 : Details of the Results of the Fall 2008 SSCI CT Post-Test

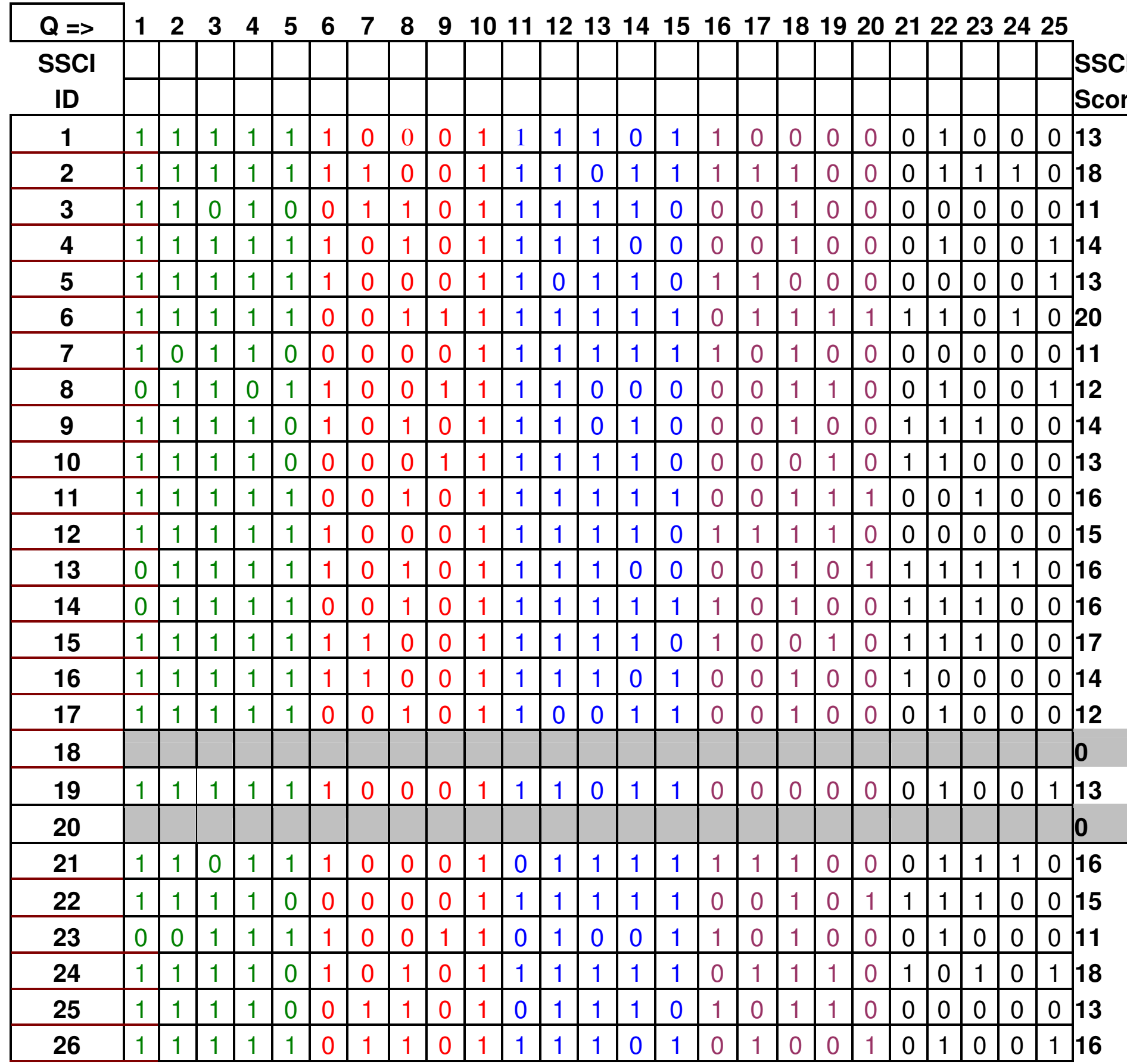

\begin{tabular}{|l|l|l|l|l|l|l|l|l|l|l|l|l|l|l|l|l|l|l|l|l|l|l|l|l|l|}
\hline \#Right & 20 & 22 & 22 & 23 & 17 & 14 & 6 & 11 & 4 & 24 & 21 & 22 & 18 & 17 & 14 & 10 & 7 & 18 & 8 & 5 & 9 & 16 & 9 & 4 & 6 \\
\hline
\end{tabular}

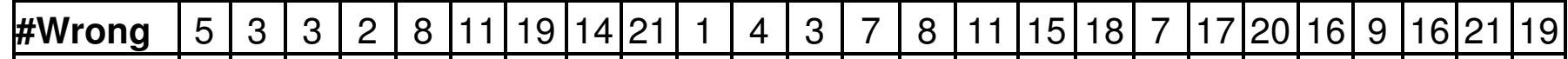

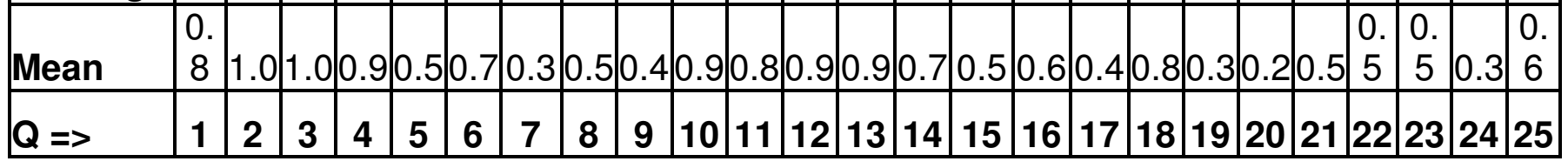


One student numbered 9 did not take the pre-test. Two students numbered 18 and 20 either dropped the class or did not take both pre- and post-tests.

The overall pre-test mean score for all the 17 students is Sum / $17=10.08$.

The maximum score is $16 / 25$. The minimum score is $8 / 25$.

The overall post-test mean score for all the 16 students is Sum / $16=13.346$.

The maximum score is $20 / 25$. The minimum score is $11 / 25$.

It was expected that Post-Test grades will be higher than Pre-Test grades. This is true except in three cases. Two cases have lower Post-Test score than Pre-Test score and one student scored the same on both Pre- and Post-Tests. To better measure the correlation between Pre-test and PostTest results, we compute $<\mathrm{g}>$ which is introduced as the normalized gain as defined and used in [2].

The $<\mathrm{g}>$ parameter (defined as $\langle\mathrm{g}>=$ (post-pre)/(100-pre)) helps us quantify student learning during the course. A positive $<\mathrm{g}>$ indicates performance improvement. The value of $100<\mathrm{g}>\%$ shows student incremental learning or gain in knowledge during the course as a percentage. See Table 8 for the $<\mathrm{g}>$ scores for Fall 2008 class.

\begin{tabular}{|c|c|c|c|c|c|c|c|c|c|}
\hline Student & $\mathbf{1}$ & $\mathbf{2}$ & $\mathbf{3}$ & $\mathbf{4}$ & $\mathbf{5}$ & $\mathbf{6}$ & $\mathbf{7}$ & $\mathbf{8}$ & $\mathbf{9}$ \\
\hline$<\mathbf{g}>$ & 0000 & 0.0238 & -0.0114 & 0.0115 & 0.0225 & 0.0909 & 0.0220 & 0.0538 & N/A \\
\hline Student & $\mathbf{1 0}$ & $\mathbf{1 1}$ & $\mathbf{1 2}$ & $\mathbf{1 3}$ & $\mathbf{1 4}$ & $\mathbf{1 5}$ & $\mathbf{1 6}$ & $\mathbf{1 7}$ & $\mathbf{1 8}$ \\
\hline$<\mathbf{g}>$ & 0.0333 & 0.0233 & 0.0341 & 0.0345 & 0.0455 & 0.0778 & 0.0115 & 0.0222 & N/A \\
\hline Student & $\mathbf{1 9}$ & $\mathbf{2 0}$ & $\mathbf{2 1}$ & $\mathbf{2 2}$ & $\mathbf{2 3}$ & $\mathbf{2 4}$ & $\mathbf{2 5}$ & $\mathbf{2 6}$ & \\
\hline$<\mathbf{g}>$ & 0.0225 & N/A & 0.0667 & 0.0659 & 0.0111 & 0.0889 & 0.0225 & 0.0345 & \\
\hline
\end{tabular}

Table 8 The $<\mathrm{g}>$ scores for Fall 2008 class.

Table 8 shows that Negative $<\mathrm{g}>$ means Post-Test result was worse than Pre-Test result. Zero $<$ g $>$ means no improvement and Positive $<$ g $>$ means Post-Test result was better than Pre-Test result which signals improved learning of signals and systems concept as a result of the course. It is clear from any of these results that the performance of the students improved at Post-test compared to Pre-Test.

Another possible way to display the result is to plot the histograms of Pre- and Post-Test results. 
Considering the individual responses to Questions 6-8 and 10-14, it is clear that the students did not fully comprehend the concepts in those particular questions. Next time we will put more emphasis on those concepts.

These questions test the transform properties with applications to pole-zero plots, Fourier series, etc. As seen from the Table 7 above, many of the students had some difficulty with these questions, especially Question 10 which only one person got right.

Many of the other questions involve relating two or more concepts such as time-domain signals, with filtering, with pole-zeros plots. These questions test the concept of convolution and its properties when applied to a Linear, time-invariant (LTI) system.

Some of the other questions involve determination of the property of a system given its input and output signals and tests the students' ability to synthesize these properties by reverse thinking processes.

We also realized the students understood the concept of Bode Plots since they have seen it in two or three classes already. The concept of graphical convolution is also well understood. We spent quite a bit of time on it during the class.

This also suggests that we need to improve our teaching styles to accommodate these students pre-disposition and ensure they learn these important concepts. 
We can also look to see if there is any direct correlation between the Overall Class Rank and the Rank in the SSCI CT Post-Test. SSCI measures conceptual understanding while the class exams measures mastery of the class subject and the overall ability to solve problems.

Table 9 below shows the comparisons between Rank in Class and Rank in Post-Test.

Table 9 : Fall 2008 Comparing Class Exam and SSCI CT Test Rankings

\begin{tabular}{|c|c|c|c|}
\hline Class ID & Rank in Class & $\begin{array}{c}\text { Rank in SSCI CT } \\
\text { Post-Test }\end{array}$ & $\begin{array}{c}\text { SSCI CT PT Grade } \\
25 / 25\end{array}$ \\
\hline 1 & 17 & 15 & 13 \\
\hline 2 & 20 & 2 & 18 \\
\hline 3 & 12 & 22 & 11 \\
\hline 4 & 8 & 12 & 14 \\
\hline 5 & 19 & 15 & 13 \\
\hline 6 & 22 & 1 & 20 \\
\hline 7 & 13 & 22 & 11 \\
\hline 8 & 1 & 20 & 12 \\
\hline 9 & 2 & 12 & 14 \\
\hline 10 & 11 & 15 & 13 \\
\hline 11 & 24 & 5 & 16 \\
\hline 12 & 23 & 10 & 15 \\
\hline 13 & 5 & 5 & 16 \\
\hline 14 & 10 & 5 & 16 \\
\hline 15 & 7 & 4 & 17 \\
\hline 16 & 16 & 12 & 14 \\
\hline 17 & 9 & 20 & 12 \\
\hline 18 & 14 & 15 & 13 \\
\hline 19 & $N / A$ & N/A & N/A \\
\hline 20 & 21 & 5 & 16 \\
\hline 21 & 4 & N/A & N/A \\
\hline 22 & 15 & 10 & 15 \\
\hline 23 & 18 & 22 & 11 \\
\hline 24 & 25 & 2 & 18 \\
\hline 25 & 3 & 15 & 13 \\
\hline 26 & 6 & 5 & 16 \\
\hline
\end{tabular}

Comparing the class rankings in the standard exams and in the SSCI CT Test (see Table 9), it is easy to see that there's a correlation between students who do well in the standard exams and those who do well in the conceptual tests. The students whose score are not correlated suggest that they may be good at solving design and mechanistic problems, requiring step-by-step procedure but not good at conceptual understanding. The reverse is also true. This also suggests that we need to improve our teaching style to accommodate these students pre-disposition to their individual learning styles. 


\section{Conclusions}

In this paper, we presented and analyzed the results of recent assessment tests in a Linear Systems course at Santa Clara University. Two specific tests are discussed. The results of both tests are analyzed. Some suggestions for future offerings of the course are also presented.

One of the major lessons learnt from this exercise is that the presentation of the material needs to be done conceptually as well as mechanically. The regular exams take care of determining the students' capability in the mechanistic methods of solving the problems. The assessment tests (especially the SSCI CT test) help us determine if the students have an understanding of the concepts of linear systems, signals and transforms. Through these assessment tests, we have been able to determine how much conceptual understanding the students have developed by the end of the class.

We also note that the SSCI Tests did not discourage guessing by penalizing it in anyway. This means students can guess answers and score well on these tests even if they did not understand the concepts. An ideal test should penalize guessing to accurately determine students' understanding of the concepts taught in class.

Our sample sizes are quite small. The statistical distribution of the results may be less than expected due to this small sample size but the trends are as expected. We intend to keep up doing these pre- and post-assessment tests for future offerings of the class. This will increase our sample sizes and we will then be able to accumulate the results over time so that the statistical

analysis of the results will become better reflective of the sample space, the student population at Santa Clara University.

Finally, we have used the results to recommend alternate pedagogical methods for presenting the material in the Linear Systems course.

In future work, we will analyze the SSCI DT Test results and compare with those of the SSCI CT Tests in prior course. We will also track the performance of the students from the CT course to the DT course.

In summary, we met the goals of our study:

(1) To determine how much conceptual understanding the students have developed by the end of the class (compared to the beginning of the class).

(2) To correlate the performance on the end-of-term exam with the performance on the SSCI Post-Test which is designed to test the conceptual understanding, but not necessarily the steps of problem solving and system design.

(3) To determine the concepts which the students have had difficulty understanding so that there may be more emphasis on those concepts the next time the course is offered.

(4) To recommend alternate pedagogical methods for presenting the material in the Linear Systems course based on the results of our study. 


\section{References}

[1] Philips, Parr and Riskin, Signals, Systems and Transforms, Prentice-Hall publishers, Third edition, 2003.

[2] Kathleen Wage et. al. "Signal and Systems Concept Inventory", IEEE Transactions on Education, vol. 48, No. 3, pp. 448-461, August 2005

[3] John Buck and Kathleen Wage, "Active and Cooperative Learning in Signal Processing", IEEE Transactions on Signal Processing, vol. 17, pp. 52-56, March 2000

[4] T. Ogunfunmi, "Analysis of Assessment Results in a Linear Systems Course", Proceedings of the ASEE Conference, June 2007. 